\title{
Erratum to: A decision support system for assessing and managing environment risk cross borders
}

\author{
K. Pediaditi • M. Stanojevic • M. Kouskouna • \\ C. Karydas • D. Zianis • George P. Petropoulos • \\ N. Boretos
}

Published online: 14 August 2014

(C) Springer-Verlag Berlin Heidelberg 2014

Erratum to: Earth Sci Inform (2011) 4:107-115

DOI 10.1007/s12145-011-0081-8

The original version of this article unfortunately contains an error in the name of the two of the authors. The name C. Kouskouna and M. Karydas were mixed up. The correct name is presentated above.

The online version of the original article can be found at http://dx.doi.org/ 10.1007/s12145-011-0081-8.

K. Pediaditi $(\bowtie) \cdot$ C. Karydas $\cdot$ D. Zianis

Department of Environmental Management, Mediterranean

Agronomic Institute of Chania, Alsylion Agrokepion, Chania, P.O.Box 185, 73100 Crete, Greece

e-mail: kalliapediaditi@hotmail.com

K. Pediaditi

Ministry of Environment, Energy and Climate Change, 17

Amaliados Str, 11523 Athens, Greece

M. Stanojevic

Mihailo Pupin Institute, Volgina 15, 11060 Belgrade, Serbia

M. Kouskouna

Faculty of Law, University of Athens (EKPA), Athens, Greece

G. P. Petropoulos

Department of Earth Sciences, University of Bristol, Queens Road,

Bristol BS8 1RJ, UK

\section{N. Boretos}

Department of Information Systems and Technology, Mediterranean Agronomic Institute Chania, Alsyllion Agrokepion, Chania, Crete 73100 , Greece 